\title{
Neonatal Emergencies in Full-term Infants: A Seasonal Description in a Paediatric Referral Hospital of Yaoundé, Cameroon
}

\author{
Georges Pius Kamsu Moyo*, Donleine Sobguemezing, Hélène Tetinou Adjifack \\ Faculty of Medicine and Biomedical Sciences, University of Yaoundé I, Yaoudé, Cameroo \\ Email address: \\ kamsuzicfried@yahoo.fr (G. P. K. Moyo) \\ ${ }^{*}$ Corresponding author \\ To cite this article: \\ Georges Pius Kamsu Moyo, Donleine Sobguemezing, Hélène Tetinou Adjifack. Neonatal Emergencies in Full-term Infants: A Seasonal \\ Description in a Pediatric Referral Hospital of Yaoundé, Cameroon. American Journal of Pediatrics. Vol. 6, No. 2, 2020 , pp. 87-90. \\ doi: $10.11648 /$ j.ajp.20200602.13
}

Received: February 9, 2020; Accepted: February 19, 2020; Published: March 6, 2020

\begin{abstract}
Background: A neonatal emergency may be defined as a potentially life-threatening disorder or anomaly which occurs within the first 28 days after birth. From an epidemiological stand point, some disorders may be specific to this period and so their knowledge may improve the management and be life-saving. Objective: To determine the various neonatal emergencies. Methodology: We carried out a cross-sectional study with prospective and exhaustive recruitment of full-term neonates presenting emergencies at the Mother and Child Centre of the Chantal Biya Foundation. The study lasted for 4 months and was conducted from September to December 2018 in Yaoundé, Cameroon. Results: The survey covered 235 neonatal emergencies, $28(11.9 \%)$ were surgical emergencies, 207 (88\%) were medical emergencies and $12(5.1 \%)$ neonates had mixed emergencies. Most cases 137 (58.2\%) occurred within the first week of life, the leading causes were sepsis 147 (62.5\%), birth asphyxia $25(10.6 \%)$ and jaundice $18(7.6 \%)$. The death rate was $3.4 \%(08)$ mainly due to congenital malformations 50\% (04) while $213(90.6 \%)$ cases recovered. Conclusion: The leading causes of neonatal emergencies found in this study were not very different from those described in the literature and so prompt diagnosis and management may further improve the outcome of neonatal emergencies, with most neonates recovering.
\end{abstract}

Keywords: Neonate, Emergency, Cameroon

\section{Introduction}

The neonatal period is a vulnerable period of infancy, and so neonates are a fragile population for which caution should be taken in management [1]. In the ill neonate, an apparently mild symptom may rapidly transform into a critical condition. Symptoms may be subtle and non-specific with slight behavioural changes such as modification in feeding being indicative of illness [1]. A neonatal emergency may be considered as a potentially life-threatening disorder or anomaly which occurs during the first 28 days after birth [2]. There exist two types, as medical emergencies may be distinguished from surgical emergencies. Neonatal emergencies significantly contribute to under-5 morbidity and mortality in developing countries, mainly because of poverty and limited access to quality health care especially in rural areas [3-5]. It may account for up to $70 \%$ of neonatal deaths registered in a service [6]. There are more than 3.8 million neonates who die during their first month of life with up to half of this occurring on the first day [7]. According to the World Health Organization, over $90 \%$ of all neonatal deaths occur in developing countries [8, 9]. Apart from poverty and low quality of health care, other factors such as late postnatal visits and poor health seeking behaviour have equally been incriminated [3]. Therefore, neonatal emergency-related poor outcomes may be reduced by the implementation of optimal antenatal care, essential newborn care and the availability of skilled birth attendants $[6,10,11]$. Despite the efforts put in place in most African countries [1214], a lot is left to be done as there persist a gap in the care for mothers and babies in the early neonatal period [15]. More over, even though interventions to provide coordinated 
program with early discharge have been shown to reduce emergency department use, early and sometimes careless discharge from newborn nurseries may be responsible for further increased emergencies in neonates $[1,16,17]$. Due to the fact that neonatal emergencies may lead to fatal complications in case of inappropriate intervention, newborns brought to the emergency department might be hospitalised or kept for keen monitoring regardless of normal laboratory findings $[1,6]$. Correct history taking, proper examination and intimate epidemiological knowledge of the spectrum of pathologies pertaining to this age group are necessary for accurate diagnosis and prompt management [1]. This study aimed at describing the various neonatal emergencies registered in a pediatric referral hospital of Yaoundé, Cameroon over a period of four months.

\section{Methodology}

We conducted a cross-sectional descriptive study at the Mother and Child Centre of the Chantal BIYA foundation, which is the principal pediatric referral hospital of the country. The hospital is situated in Yaoundé, the capital of Cameroon and as well the main town of the Centre region. It is a cosmopolite city and one of the two most densely populated towns of the country, with an average population close to 4.100 .000 inhabitants. The hospital has most pediatric specialists and is optimally equipped for the management of sick neonates and children at large.

The study lasted for a period of four months, from September to December 2018. Ethical clearance was requested and obtained from the research and ethical committee. The recruitment of neonates brought to the emergency unit was prospective and exhaustive over the period of study. Premature neonates were excluded from the study. Potential life-threatening disorders or anomalies occurring during the first 28 days after birth were considered as neonatal emergencies.

There exist a symptomatic or systemic classification of neonatal emergencies which may contrast with the syndromic or diagnostic classification. The advantage of the later classification is the immediate possibility to initiate a holistic management. We used a combination of both classifications known as "THE MISFITS" approach of neonatal emergency which features Trauma, Heart disease (Hypoxia/Hypovolemia), Endocrine, Metabolic, Inborn errors of metabolism, Sepsis, Formula mishaps, Intestinal catastrophes, Toxins/poisons, and Seizures. The diagnosis of birth asphyxia and hypoxic ischemic encephalopathy was based on Apgar score and Sarnat's criteria, whereas jaundice was based on the presence of hyperbilirubinemia. Sepsis was characterized by the presence of risk factors; a symptomatic infant with abnormal C-Reactive Proteins (CRP) and Complete Blood Count (CBC) or positive blood culture. Silverman's classification was used for respiratory distress. Ultrasound, CT-scan and radiologic imaging were done when indicated, especially in case of malformations and other surgical emergencies. Clinical records and laboratory reports of the participants were equally reviewed to document their definitive diagnoses.

\section{Results}

The survey covered 235 neonatal emergencies. There were 147 males and 88 females and a sex ratio of 1.7:1. Out of the 235 neonatal emergencies, $28(11.9 \%)$ were surgical emergencies and 207 (88\%) were medical emergencies. Twelve neonates $(5.1 \%)$ had mixed emergencies. In average, infants with surgical emergencies were brought after 4.2 days with an outcome after management being favorable in 23 $(82.1 \%)$ cases. The various surgical emergencies and their frequencies are shown on table 1 below.

Table 1. Surgical emergencies.

\begin{tabular}{lll}
\hline Variable & Frequency $(\mathbf{n}=\mathbf{2 8})$ & Percentage (\%) \\
\hline Spina bifida & 07 & 25.0 \\
Polymalformation syndrome & 06 & 21.4 \\
Ano-rectal malformation & 05 & 17.8 \\
Intestinal occlusion & 05 & 17.8 \\
Omphalocele & 05 & 17.8 \\
\hline
\end{tabular}

Most patients 137 (58.2\%) were brought to consultation within the first week of life. The average stay in hospital was 8.5 days before neonates got well. We registered a death rate of $3.4 \%$ ( 8 cases) with such babies having spent 6.5 days of non-effective treatment. Fourteen neonates (5.9\%) were taken away by their families against medical advice while $213(90.6 \%)$ were normally followed-up and discharged after recovery. Table 2 shows the various medical emergencies encountered.

Table 2. Medical emergencies.

\begin{tabular}{lll}
\hline Variable & Frequency $(\mathbf{n}=\mathbf{2 0 7})$ & Percentage $(\mathbf{\%})$ \\
\hline Sepsis & 147 & 71.0 \\
Birth asphyxia & 25 & 12.0 \\
Jaundice & 18 & 8.7 \\
Metabolic disorder & 09 & 4.3 \\
ALTE & 05 & 2.9 \\
Birth injury & 02 & 0.9 \\
CAH & 01 & 0.5 \\
\hline
\end{tabular}

*ALTE: Apparent Life Threatening Event.

*CAH: Congenital Adrenal Hyperplasia.

Out of 147 neonates with sepsis, $57(38.7 \%)$ where of early onset, no focus was found in 88 cases (59.8\%), while the pulmonary focus was the most frequent in over 35 cases $(59.3 \%)$. The most occurring metabolic disorder was hypoglycemia in 06 cases $(66.6 \%)$, followed by hypocalcaemia in 02 neonates $(22.2 \%)$. Table 3 shows the case fatality rates with sepsis being the leading cause of deaths taken individually $37.5 \%$ (3) and congenital malformations predominating on a cumulative basis $50 \%$ (4).

Table 3. Case fatality rates.

\begin{tabular}{lll}
\hline Variable & Frequency $(\mathbf{n}=\mathbf{8})$ & Percentage $(\%)$ \\
\hline Sepsis & 03 & 37.5 \\
Polymalformation & 02 & 25.0 \\
\hline
\end{tabular}




\begin{tabular}{lll}
\hline Variable & Frequency $(\mathbf{n}=\mathbf{8})$ & Percentage $(\%)$ \\
\hline Omphalocele & 01 & 12.5 \\
Ano-rectal malformation & 01 & 12.5 \\
Intestinal occlusion & 01 & 12.5 \\
\hline
\end{tabular}

\section{Discussion}

In this survey, neonatal medical emergencies were predominant over surgical emergencies whereas a highest death rate was registered among neonates presenting surgical emergencies. In effect, contrarily to other studies of neonatal emergencies, a particularity of our study is to have analysed simultaneously medical and surgical emergencies $[3,6,18$, 19]. This was possible because of the availability of a surgical department in our study site, whereas other researchers could either deal with medical or surgical emergencies and not both $[3,18]$. Like wise the lower death rate $(3.4 \%)$ registered may equally be due to the fact that we conducted our study in one of the best pediatric referral centers of the country with higher standards in terms of human resources and medical equipment. Other studies registered higher death rates, but in settings with lower standards and with relatively larger samples [3, 6, 18, 19]. The overall deadliest emergencies were surgical (62.5\%) including malformations. This is consistent with other studies where death rates due to surgical emergencies were as high as $68 \%$ of all neonatal deaths in the setting $[6,19]$. The main contributing factor to this may be "delayed consultation" with an average of 4.2 days in our series. Even though prenatal diagnosis and mothers' education might prompt timely intervention, delays in management of sick neonates almost always lead to deleterious complications as well as poor post-operative follow-up [1, 20, 21].

The three most occurring neonatal emergencies were sepsis, birth asphyxia and jaundice. This is not very different from the World Health Organization's estimates which presents severe infections $(26 \%)$, birth asphyxia $(23 \%)$ and preterm birth $(28 \%)$ as the three most common causes of neonatal deaths [7]. Preterm birth could not feature among neonatal emergencies in our survey given that our study population was made of full-term infants only. Some other authors also described jaundice as being a major neonatal emergency in contexts similar to ours $[6,22,23]$. In most studies, sepsis appears as a recurrent neonatal emergency probably because of neonates' immature immune system and their early exposition to infectious agents $[1,3,6]$.

More than $50 \%$ of neonates who presented with an emergency were aged less than a week. This confirms that the first week of life is one of the most vulnerable and riskiest, as demonstrated by other studies [6]. Although most of the emergencies can occur during this period, many of them could however be prevented by improvement of pregnancy follow-up, optimal essential newborn care, anticipatory guidance through newborn check-ups and parents counseling [24].

The main cause of surgical emergencies in our survey were congenital malformations, and this is in vein with findings from a number of researches conducted on the African continent $[18,6,19]$. In effect, preventable pathologies such as spina bifida which was predominant, points out the necessity to reinforce antenatal prophylaxis such as folic acid supplementation.

The Mother and Child Centre of the Chantal Biya Foundation is a non-lucrative referral centre with multiple subventions from philanthropic partners, and so most interventions are facilitated, assuring prompt management of ill children.

\section{Conclusion}

Neonatal emergencies in this study were predominated by medical emergencies with the leading causes of all emergencies in full-term neonates being sepsis, birth asphyxia, and jaundice. On the other hand, surgical emergencies were the deadliest with congenital malformations predominating. These results are not very different from those described in the literature and so a mastery of these pathologies may help for prevention and prompt management of cases, thereby ameliorating the outcome of neonatal emergencies in our context.

\section{Author Contributions}

The $1^{\text {st }}$ author contributed to all steps, the $2^{\text {nd }}$ and $3^{\text {rd }}$ authors participated in data collection and analysis.

\section{Funding}

Private.

\section{Ethical Approval}

The study was approved by the Institutional Ethics Committee.

\section{Acknowledgements}

Hospitals authorities, all collaborators to the project.

\section{References}

[1] Barousseau T, Sharieff GQ. Newborn emergencies: the first 30 days of life. Pediatr Clin North Am. 2006; 53 (1): 69-84.

[2] Neonatal EmergenciesMedscape Emergency Medicine. Available from: http://www.medscape.org/viewarticle/557824. [Last accessed 2014 August 08].

[3] Abiodun MT, Oluwafemi RO. Spectrum and outcome of neonatal emergencies seen in a free health-care program in South-Western Nigeria. Niger J Clin Pract 2017; 20: 283-9.

[4] Lawn JE, Kinney MV, Black RE, Pitt C, Cousens S, Kerber K, et al. Newborn survival: A multi-country analysis of a decade of change. Health Policy Plan 2012; 27: 6-28. 
[5] Mukhtar-Yola M, Iliyasu Z. A review of neonatal morbidity and mortality in Aminu Kano Teaching Hospital, northern Nigeria. Trop Doct 2007; 37: 130-2.

[6] Abdulkadir I, Hassan L, Abdullahi FL, Purdue S, Adebiyi NM, Abubakar Y, Adeoye G, Ogala WN. Common Neonatal Emergencies in Zaria. Sub-Saharan Afr J Med 2017; 4: 26-30.

[7] Lawn JE, Cousens S, Zupan J. 4 million neonatal deaths: when? where? why? Lancet 2005; 365: 891-900.

[8] Lawn JE, Lee AC, Kinney M, Sibley L, Carlo WA, Paul VK, et al. Two million intrapartum-related stillbirths and neonatal deaths: Where, why, and what can be done? Int J Gynaecol Obstet 2009; 107 (Suppl 1): S5-19.3.

[9] World Health Organization. Neonatal and Perinatal Mortality: Country, Regional, and Global estimates. Geneva, Switzerland: World Health Organization; 2004. Available from: http://www. whqlibdoc.who.int/publications/2007/9789241596145.pdf. [Searched on 2015 Nov 26].

[10] CDC: Infant Mortality. Available from: http://www.cdc.gov/ reproductivehealth/MaternalInfantHealth/InfantMortality.htm. [Last accessed on $2015 \mathrm{Jul} 20$ ].

[11] Segrè S, Coffey P, Metzler M, Villadiego S, Brandes N, Hodgins $\mathrm{S}$, et al. Chlorhexidine for umbilical cord care. A case study prepared for the UN Commission on life-saving commodities for women and children. February, 2012. Available http://www.pdf.usaid.gov/pdf_docs/pnady705.pdf [Last accessed 2016 Jan 12].

[12] Zimba E, Kinney MV, Kachale F, Waltensperger KZ, Blencowe H, Colbourn T, et al. Newborn survival in Malawi: A decade of change and future implications. Health Policy Plan 2012; 27: Suppl 3iiis8-103.

[13] Ogundipe OL. Experiences of women participating in a safe motherhood (Abiye) project in Ondo State of Nigeria. Int J Cur Microbiol App Sci 2013; 2: 148-61.
[14] FMOH and Saving Newborn Lives Program Nigeria State Data Profiles: An Accountability Tool for Maternal, Newborn and Child Health in Nigeria. Available from: http://www.healthynewbornnetwork.org/resource/nigeriastate-data-profiles. [Last accessed on 2015 Nov 26].

[15] Lawn J, Kerber K, Enweronu-Laryea C, Massee Bateman O. Newborn survival in low resource settings - are we delivering? BJOG 2009; 116 (Suppl. 1): 49-59.

[16] Millar KR, Gloor JE, Wellington N, Joubert GI. Early neonatal presentations to the pediatric emergency department. Pediatric emergency care. 2000; 16 (3): 145-50.

[17] Sacchetti AD, Gerardi M, Sawchuk P, Bihl I. Boomerang babies: emergency department utilization by early discharge neonates. Pediatric emergency care. 1997; 13 (6): 365-8.

[18] Ilori I, Ituen A, Eyo C. Factors associated with mortality in neonatal surgical emergencies in a developing tertiary hospital in Nigeria. Open J Pediatr. 2013; 3 (3): 231-235.

[19] Dicko-Traoré F, Diall H, Koné I, Samaké B, Coulibaly O, Amadou I, et al. Neonatal Surgical Emergencies in Gabriel Touré Teaching Hospital in Bamako: Epidemiological and Clinical Aspects. Pediatr Neonat biol 2019, 4 (1): 000133.

[20] Taguchi T, Nagata K, Kinoshita Y, Esumi G. Progress in and outcomes of neonatal surgery over the past 50 years. Nihon Geka Gakkai Zasshi 2014; 115 (6): 306-311.

[21] Ekenze SO, Ajuzieogu OV, Nwomeh BC. Challenges of management and outcome of neonatal surgery in Africa: a systematic review. Pediatr Surg Int. 2016; 32 (3): 291-299.

[22] Owa JA, Osinaike AI. Neonatal morbidity and mortality in Nigeria. Indian J Pediatr 1998; 65: 441-9.

[23] Ekanem EE. Causes of neonatal and postneonatal mortality in Nigerian children. Early Child Dev Care 1990; 57: 9-13.

[24] Lee HC, Bardach NS, Maselli JH, Gonzales R. Emergency department visits in the neonatal period in the United States. 2014; 30 (5): 315-8. 